\title{
Risk factors associated with pre-term birth in Dar es Salaam, Tanzania: a case-control study
}

\author{
FANAKA A. MAHAPULA ${ }^{1}$, KITINDI KUMPUNI ${ }^{2}$, JOYCE P. MLAY ${ }^{3}$ and THERESIA F. MREMA ${ }^{3 *}$ \\ ${ }^{1}$ Kairuki Hospital, Department of Obstetrics and Gynaecology, Dar es Salaam Tanzania \\ ${ }^{2}$ Hubert Kairuki Memorial University, Department of Obstetrics \& Gynaecology, Dar es Salaam, Tanzania \\ ${ }^{3}$ Hubert Kairuki Memorial University, Department of Community Health Nursing, Dar es Salaam, Tanzania
}

\begin{abstract}
Background: Preterm birth remains one of the most serious problems in obstetrics care. Its aetiology is complex and multifactorial. This study was carried out to determine risk factors for preterm birth in Dar es Salaam City in Tanzania.

Methods: This case-control study was conducted in three municipal hospitals namely, Amani, Mwananyamala and Temeke in Dar es Salaam. It involved 377 pairs of women with preterm birth (cases) and term birth (controls). Eligible women who agreed to participate and who signed the consent form completed a short interview regarding demographic and lifestyle factors, had their baby examined for maturity, and had their medical records abstracted. All cases and controls were interviewed face-to-face using a specially designed questionnaire. Multivariate logistic regression after controlling for potential confounders was used to measure the strength of associations between preterm birth and related factors. Results: Several significant risk factors associations with pre-term birth were multiple pregnancies $(A O R=$ 8.6; 95\% Cl 4.5-16.5; $p$-value <0.001), untreated vaginal discharge ( $A O R=5.2 ; 95 \% \mathrm{Cl} 1.1-24.4 ; p$-value 0.034$)$, public prenatal care $(A O R=2.1 ; 95 \% \mathrm{Cl}$ 1.1-4.1; $\mathrm{p}$-value 0.017), untreated urinary tract infection $(\mathrm{AOR}=2.7$; $95 \% \mathrm{Cl}$ 1.2-6.1; $\mathrm{p}$-value 0.016), complication during pregnancy $(\mathrm{AOR}=2.7 ; 95 \% \mathrm{Cl} 1.3-5.3 ; \mathrm{p}$-value 0.004$)$, cervical incompetence $(A O R=11.6 ; 95 \% \mathrm{Cl} 1.1-121.5 ; \mathrm{p}$-value 0.04$)$, polyhydramnios $(\mathrm{AOR}=8.3 ; 95 \% \mathrm{Cl} 1.7-40.2$; p-value 0.008), and lack of antenatal visits ( $A O R=5.1 ; 95 \% \mathrm{Cl} 1.4-17.8$; $p$-value 0.042 ).

Conclusion: This study has identified several risk factors for preterm birth in the city of Dar es Salaam. It is important that planners design community-based interventions to address complications from preterm birth.
\end{abstract}

Keywords: preterm birth, risk factors, obstetric care, Tanzania

\section{Introduction}

Preterm birth is defined as all births before 37 completed weeks of gestation or fewer than 259 days since the first day of a woman's last menstrual period (Beck et al., 2010; WHO, 2015). Preterm birth can be further sub-divided based on gestational age: extremely preterm $(<28$ weeks), very preterm ( 28 - <32 weeks) and moderate preterm ( $32-<37$ completed weeks of gestation) (WHO, 2015). Preterm birth remains an extremely common adverse outcome of pregnancy accounting for $5-18 \%$ of all deliveries. It is estimated that about 1 million children die each year due to complications of pre-term birth (WHO, 2015). In almost all high- and middleincome countries, preterm birth is the leading cause of child death under the age of 5 (Lawn et al., 2013). In Tanzania, pre-term birth account for $18.5 \%$ of all perinatal deaths (Mpembeni et al., 2015).

Preterm birth is a syndrome with a diversity of causes which can be grouped into two broad subtypes: spontaneous preterm birth defined as spontaneous onset of labour or following pre-labour premature rupture of membranes and provider-initiated preterm birth, defined as induction of labour or elective caesarean birth before 37 completed weeks of gestation for maternal or foetal indications, or other non-medical reasons.

Intervening preterm birth is crucial for accelerating steps forward towards reduction of child mortality. Besides its significant contribution to mortality, the effect of preterm birth

\footnotetext{
*Correspondence Email:tedymrema@gmail.com
} 
amongst some survivors may continue throughout life, impairing neuro-developmental functioning (Blencowe et al., 2013), learning impairment and visual disorders and affecting longterm physical health with a higher risk of disease (Cooper et al., 2009; Pike \& Lucas, 2015). These effects exert a heavy burden on families, society (Gondwe et al., 2014) and the health system (Lawn et al., 2013). Hence, preterm birth is one the largest single conditions in the Global Burden of Disease analysis given the high mortality and the considerable risk of lifelong impairment (Murray et al., 2012).

Preterm birth is a complex problem with a set of overlapping determinants factors. Risk factors may include socio-demographic characteristics, obstetrics history and medical conditions (Alexander, 2007). Many of these factors occur in combination, particularly in those who are socioeconomically disadvantaged. Detection of at-risk women and their risk factors for preterm birth is important for initiation of risk-specific interventions and preventive strategies. We therefore, conducted a case-control study to determine risk factors associated with preterm birth in Dar es Salaam, Tanzania.

\section{Materials and Methods}

\section{Study area}

The study was conducted in Dar es Salaam, the largest city in Tanzania with a population of about 4,364,541 (NBS, 2013). The study involved three municipal hospitals of Amana, Mwananyamala and Temeke. These hospitals are located in Ilala, Kinondoni and in Temeke districts, respectively and they all saved as referral hospital. During the nine-month period from 1 September 2013 to 31 May 2014 cases and controls were selected from the three main maternity blocks of the three hospitals. The Maternity blocks of the hospitals provide health-care services in neonatology, obstetrics and gynaecology. The daily deliveries range from 60 to 80 in Amana, 40 to 50 in Mwananyamala and 50 to 60 in Temeke.

\section{Study design and participants}

The design of this study was 1:1 case-control study. Cases were defined as women with a live preterm birth (29-<37 weeks). Controls were defined as women admitted to the same hospitals with a full-term live birth ( $\geq 37$ weeks). All eligible cases present during the study hospital visits were approached in the postpartum recovery room following the birth.

\section{Data collection}

From Monday to Friday at 8:00 to 14:00hrs, a list of women was made from the delivery registry book. Eligible women who agreed to participate and who signed the consent form completed a short interview regarding demographic and lifestyle factors, had their baby examined for maturity, and had their medical records abstracted. All cases and controls were interviewed faceto-face using a specially designed questionnaire. Age of mother was calculated as the number of years from her date of birth to her previous birthday. Information on marital status, education of mother and occupation status of mother were sought during the interview.

Information about suspected risk factors for the present pregnancy and past obstetric history were obtained from the patient and/or from the clinical case record as applicable. The respondents were also asked about the diagnosis and treatment of urinary tract infections (UTI) and perceived abnormal vaginal discharge. Reported abnormal vaginal discharge associated with at least one of the following symptoms: itching, dysuria, dyspareunia, odour, and non-white colour.

In this study, a respondent was classified as having complication during pregnancy if she had one or more of these conditions: vaginal bleeding, anaemia, eclampsia/ pre-eclampsia, excessive nausea/vomiting. Interviewers coded the complete questionnaires at the end of each data collection day. 


\section{Data analysis}

Data from the questionnaire were entered into a computer using SPSS Version 20 followed by data cleaning and generation of frequency distribution tables. Association of the risk factors under study was assessed by applying Chi-square $\left(\chi^{2}\right)$ test at a significant level $p<0.05$. To assess the strength of association between dependent and independent variables, logistic regression analysis was done and Odds Ratios (OR) and 95\% Confidence Intervals $(\mathrm{Cl})$ for the OR was obtained. The $p$-value was based on the value of $Z$; a $p$ value $<0.05$ was significant.

\section{Ethical considerations}

Ethical clearance for conducting the research was obtained from the Institutional Review Board of the Hubert Kairuki Memorial University. Permission to carry out the study was obtained from Municipal Administration and in the Hospitals in which study was conducted. Consent was obtained from each participating woman, while being assured of confidentiality and anonymity and only those consented were interviewed.

\section{Results}

During the study period, a total of 377 case-control pairs were included in the study. Majority (73.9\%) of respondents aged between $18-34$ years and only $10.5 \%$ were formally employed. Nearly three-quarters $(72.1 \%)$ had primary education and most $(82.4 \%)$ of them were in marital union (Table 1).

\begin{tabular}{|c|c|c|c|}
\hline Variable & Response & Number & Percent \\
\hline \multirow[t]{3}{*}{ Maternal Age } & $<18$ years & 115 & $15 \cdot 3$ \\
\hline & $18-34$ years & 557 & 73.9 \\
\hline & $35+$ years & 82 & 10.9 \\
\hline \multirow[t]{2}{*}{ Marital Status } & In Union & 621 & 82.4 \\
\hline & Not In Union & 133 & 17.6 \\
\hline \multirow[t]{3}{*}{ Education Level } & Primary Education & 544 & 72.1 \\
\hline & Secondary Education & 181 & 24.0 \\
\hline & College & 29 & 3.8 \\
\hline \multirow[t]{3}{*}{ Occupation } & Formal Employed & 79 & 10.5 \\
\hline & Self Employed & 308 & 40.8 \\
\hline & Housewife & 367 & 48.7 \\
\hline
\end{tabular}

In comparison with women who gave birth to term babies in this sample, a slightly higher proportion of women with pre-term babies were more likely to be housewives $\left(\chi^{2}=9.017, p-=\right.$ $0.011)$, living without partner $\left(\chi^{2}=5.706, p=0.017\right)$, and having college education $\left(\chi^{2}=8.320, p=\right.$ $0.016)$. Many respondents who gave birth to pre-term babies reported to have previous pre-term baby $\left(\chi^{2}=5.593, p=0.018\right)$ and multiple pregnancies $\left(\chi^{2}=51.995, p<0.001\right)$ compared to their counterparts. They also reported to have had increased number of abortion $\left(\chi^{2}=11.245, p=0.004\right)$ and shorter duration of pregnancy interval $\left(\chi^{2}=16.246, p<0.001\right)$. Cervical incompetence $\left(\chi^{2}=14.570, p<0.001\right)$ and polyhydramnios $\left(\chi^{2}=22.414, p<0.001\right)$ were also reported mostly by respondents who gave birth to pre-term (Table 2 ). 
Table 2: Association between socio-demographic characteristics, obstetrics factors with birth outcome

\begin{tabular}{|c|c|c|c|c|c|}
\hline \multirow[t]{2}{*}{ Variable } & \multirow[t]{2}{*}{ Response } & \multicolumn{2}{|c|}{ Pregnancy Outcome } & \multirow[t]{2}{*}{$x^{2}$} & \multirow[t]{2}{*}{ p-value } \\
\hline & & Pre-term & Term & & \\
\hline \multirow[t]{3}{*}{ Maternal Age } & $<18$ years & $60(52.2 \%)$ & $55(47.8 \%)$ & 4.131 & 0.127 \\
\hline & 18-34 years & $268(48.1 \%)$ & $289(51.9 \%)$ & & \\
\hline & $35+$ years & $49(59.8 \%)$ & $33(40.2 \%)$ & & \\
\hline \multirow[t]{2}{*}{ Marital Status } & In Union & $298(48 \%)$ & $323(52 \%)$ & 5.706 & $0.017^{*}$ \\
\hline & Not In Union & $79(59.4 \%)$ & $54(40.6 \%)$ & & \\
\hline \multirow[t]{3}{*}{ Education Level } & Primary & $286(52.6 \%)$ & $258(47.4 \%)$ & 8.320 & $0.016 *$ \\
\hline & Secondary & $74(40.9 \%)$ & $107(59.1 \%)$ & & \\
\hline & College & $17(58.6 \%)$ & $12(41.4 \%)$ & & \\
\hline \multirow[t]{3}{*}{ Occupation } & Employed & $29(36.7 \%)$ & $50(63.3 \%)$ & 9.017 & $0.011 *$ \\
\hline & Self Employed & $148(48.1 \%)$ & $160(51.9 \%)$ & & \\
\hline & Housewife & $200(54 \cdot 5 \%)$ & $167(45.5 \%)$ & & \\
\hline \multirow[t]{3}{*}{ Parity } & $0-2$ & $250(48.4 \%)$ & $267(51.6 \%)$ & 2.383 & 0.304 \\
\hline & $3-4$ & $105(52.5 \%)$ & $95(47.5 \%)$ & & \\
\hline & $5^{+}$ & $22(59.5 \%)$ & $15(40.5 \%)$ & & \\
\hline \multirow[t]{2}{*}{ Planned Pregnancy } & No & $139(54.7 \%)$ & $115(45 \cdot 3 \%)$ & 3.420 & 0.064 \\
\hline & Yes & $238(47.6 \%)$ & $262(52.4 \%)$ & & \\
\hline \multirow{2}{*}{$\begin{array}{l}\text { Previous pre-term } \\
\text { baby }\end{array}$} & None & $327(48.5 \%)$ & $347(51.5 \%)$ & 5.593 & $0.018 *$ \\
\hline & $1+$ & $50(62.5 \%)$ & $30(37.5 \%)$ & & \\
\hline \multirow[t]{3}{*}{ Number of Abortion } & 0 & $284(47 \%)$ & $320(53 \%)$ & 11.245 & $0.004^{*}$ \\
\hline & 1 & $67(60.4 \%)$ & $44(39.6 \%)$ & & \\
\hline & $1+$ & $26(66.7 \%)$ & $13(33 \cdot 3 \%)$ & & \\
\hline \multirow{3}{*}{$\begin{array}{l}\text { Interval between } \\
\text { pregnancies }\end{array}$} & $<2$ & $72(67.9 \%)$ & $34(32.1 \%)$ & 16.246 & $<0.001 *$ \\
\hline & $2+$ & $165(46.0 \%)$ & $194(54.0 \%)$ & & \\
\hline & $1^{\text {st }}$ time & $140(48.4 \%)$ & $149(51.6 \%)$ & & \\
\hline \multirow[t]{2}{*}{ Type of pregnancy } & Singleton & $296(45 \%)$ & $362(55 \%)$ & 51.995 & $<0.001 *$ \\
\hline & Multiple & $81(84.4 \%)$ & $15(15.6 \%)$ & & \\
\hline \multirow{4}{*}{$\begin{array}{l}\text { Cervical } \\
\text { Incompetence } \\
\text { Polyhydramnios }\end{array}$} & No & $360(48.9 \%)$ & $376(51.1 \%)$ & 14.570 & $<0.001 *$ \\
\hline & Yes & $17(94.4 \%)$ & $1(5.6 \%)$ & & \\
\hline & No & $350(48.3 \%)$ & $375(51.7 \%)$ & 22.414 & $<0.001 *$ \\
\hline & Yes & $27(93.1 \%)$ & $2(6.9 \%)$ & & \\
\hline
\end{tabular}

A substantial proportion of women who reported to suffer from pregnancy induced hypertension $\left(\chi^{2}=7.145, p=0.008\right)$, urinary tract infection (UTI) $\left(\chi^{2}=10.464, p=0.005\right)$, chronic diseases (asthma or diabetes) $\left(\chi^{2}=21.935, p<0.001\right)$ and complications during pregnancy $\left(\chi^{2}=32.296, p<0.001\right)$ and had pre-term birth. Vaginal discharge $\left(\chi^{2}=17.716, p<0.001\right)$ was highly reported by respondents in pre-term birth group (Table 3 ).

Table 3: Association between medical conditions with birth outcomes

\begin{tabular}{|c|c|c|c|c|c|}
\hline \multirow[t]{2}{*}{ Variable } & \multirow[t]{2}{*}{ Response } & \multicolumn{2}{|c|}{ Pregnancy Outcome } & \multirow[t]{2}{*}{$x^{2}$} & \multirow[t]{2}{*}{ p-value } \\
\hline & & Pre-term & Term & & \\
\hline \multirow[t]{3}{*}{ Vaginal Discharge } & No & $345(48.3 \%)$ & $370(51.7 \%)$ & 17.716 & $<0.001^{*}$ \\
\hline & Yes, Untreated & $17(89.5 \%)$ & $2(10.5 \%)$ & & \\
\hline & Yes, Treated & $15(75 \%)$ & $5(25 \%)$ & & \\
\hline \multirow[t]{3}{*}{ UTI } & No & $325(48.1 \%)$ & $350(51.9 \%)$ & 10.464 & $0.005^{*}$ \\
\hline & Yes, Untreated & $19(65.5 \%)$ & $10(34.5 \%)$ & & \\
\hline & Yes, Treated & $33(68.8 \%)$ & $15(31.2 \%)$ & & \\
\hline \multirow[t]{2}{*}{ Chronic diseases } & No & $336(47.7 \%)$ & $368(52.3 \%)$ & 21.935 & $<0.001 *$ \\
\hline & Yes & $41(82 \%)$ & $9(18 \%)$ & & \\
\hline \multirow[t]{2}{*}{ Hypertension } & No & $314(48.1 \%)$ & $339(51.9 \%)$ & 7.145 & $0.008 *$ \\
\hline & Yes & $63(62.4 \%)$ & $38(37.6 \%)$ & & \\
\hline \multirow[t]{2}{*}{ Complication } & No & $279(45.1 \%)$ & $339(54.9 \%)$ & 32.296 & $<0.001 *$ \\
\hline & Yes & $98(72.1 \%)$ & $38(27.9 \%)$ & & \\
\hline
\end{tabular}


Poor attendance to antenatal care clinic $\left(\chi^{2}=138.590, p<0.001\right)$, smoking history $\left(\chi^{2}=4.658\right.$, $p=0.031)$ and anxiety/ depression $\left(\chi^{2}=12.244, p=0.007\right)$ were reported most by respondents who gave birth to pre-term babies $(p<0.05)$. Attendance to public pre-natal care $\left(\chi^{2}=8.121, p=0.004\right)$ was reported to have a protective effect against pre-term birth. Multivariate logistic regression after controlling for potential confounders was done, and factors which were significantly associated with high likelihood of pre-term birth included multiple pregnancies (AOR=8.6; $95 \% \mathrm{Cl}$, 4.5-16.5) and untreated UTI (AOR=2.7; $95 \% \mathrm{Cl}, 1.2-6.1)$. Respondents who gave birth to pre-term babies had significantly high odds of reported to have complications during pregnancy $(A O R=2.7$; $95 \% \mathrm{Cl}, 1.3-5.3)$, cervical incompetence $(A O R=11.6 ; 95 \% \mathrm{Cl}, 1.1-121.5)$ and polyhydramnios (AOR=8.3; $95 \% \mathrm{Cl}, 1.7-40.2)$. Likewise untreated vaginal discharge $(A O R=5.2 ; 95 \% \mathrm{Cl}, 1.1-24.4)$ and lack of antenatal care visit $(A O R=5.1 ; 95 \% \mathrm{Cl}, 1.4-17.8)$ were highly reported by respondents with pre-term babies than their counterpart (Table 5).

Table4: Association between lifestyle and birth outcome

\begin{tabular}{|c|c|c|c|c|c|}
\hline \multirow[t]{2}{*}{ Variable } & \multirow[t]{2}{*}{ Response } & \multicolumn{2}{|c|}{ Pregnancy Outcome } & \multirow[t]{2}{*}{$x^{2}$} & \multirow[t]{2}{*}{ p-value } \\
\hline & & Pre-term & Term & & \\
\hline \multirow{2}{*}{$\begin{array}{ll}\text { Work } & \text { during } \\
\text { pregnancy } & \end{array}$} & No & $135(48.7 \%)$ & $142(51.3 \%)$ & \multirow[t]{2}{*}{0.251} & \multirow[t]{2}{*}{0.616} \\
\hline & Yes & $241(50.6 \%)$ & $235(49.4 \%)$ & & \\
\hline \multirow[t]{3}{*}{ Antenatal Visits } & 0 & $18(75 \%)$ & $6(25 \%)$ & \multirow[t]{3}{*}{138.590} & \multirow[t]{3}{*}{$<0.001 *$} \\
\hline & $1-3$ & $282(67.6 \%)$ & $135(32.4 \%)$ & & \\
\hline & $4+$ & $77(24.6 \%)$ & $236(75.4 \%)$ & & \\
\hline \multirow[t]{2}{*}{ Public Prenatal care } & No & $56(64.4 \%)$ & $31(35.6 \%)$ & \multirow[t]{2}{*}{8.121} & \multirow[t]{2}{*}{$0.004 *$} \\
\hline & Yes & $321(48.1 \%)$ & $346(51.9 \%)$ & & \\
\hline \multirow[t]{2}{*}{ Smoking } & No & $366(49.5 \%)$ & $374(50.5 \%)$ & \multirow[t]{2}{*}{4.658} & \multirow[t]{2}{*}{$0.031^{*}$} \\
\hline & Yes & $11(78.6 \%)$ & $3(21.4 \%)$ & & \\
\hline Emotional & None & $346(48.5 \%)$ & $367(51.5 \%)$ & \multirow[t]{4}{*}{12.244} & \multirow[t]{4}{*}{$0.007 *$} \\
\hline \multirow[t]{3}{*}{ Disturbances } & Severe fight & $1(100 \%)$ & $0(0 \%)$ & & \\
\hline & Anxiety & $25(78.1 \%)$ & $7(21.9 \%)$ & & \\
\hline & Depression & $5(62.5 \%)$ & $3(37.5 \%)$ & & \\
\hline
\end{tabular}

Table 5: Pre-term risk factors before and after controlling for potential confounders

\begin{tabular}{|c|c|c|c|c|c|c|c|}
\hline \multirow[t]{2}{*}{ Variable } & \multirow[t]{2}{*}{ Response } & \multicolumn{3}{|c|}{ Crude } & \multicolumn{3}{|c|}{ Adjusted } \\
\hline & & OR & $95 \% \mathrm{Cl}$ & p-value & OR & $95 \% \mathrm{Cl}$ & p-value \\
\hline \multirow[t]{3}{*}{ Vaginal Discharge } & No & 1 & & & 1 & & \\
\hline & Yes, Untreated & 3.2 & $1.1-8.9$ & 0.025 & 5.2 & $1.1-24.4$ & $0.034 *$ \\
\hline & Yes, Treated & 0.3 & $0.6-2.1$ & 0.252 & 1.6 & $0.2-15.2$ & 0.640 \\
\hline \multirow[t]{3}{*}{ UTI } & No & 1 & & & 1 & & \\
\hline & Yes, Untreated & 2.3 & $1.2-4 \cdot 4$ & 0.007 & 2.7 & $1.2-6.1$ & $0.016 *$ \\
\hline & Yes, Treated & 1.1 & $0.4-3.1$ & 0.769 & 1.7 & $0.4-6.0$ & 0.412 \\
\hline \multirow[t]{3}{*}{ Antenatal Visits } & $4+$ & 1 & & & 1 & & \\
\hline & $1-3$ & 1.4 & $0.5-3.7$ & 0.453 & 0.8 & $0.2-2.9$ & 0.798 \\
\hline & 0 & 9.1 & $3.5-23.9$ & $<0.001$ & 5.1 & $1.4-17.8$ & $0.012 *$ \\
\hline \multirow{2}{*}{$\begin{array}{l}\text { Public prenatal } \\
\text { care }\end{array}$} & No & 1 & & & 1 & & \\
\hline & Yes & 1.9 & $1.2-3.1$ & 0.005 & 2.1 & $1.1-4.1$ & $0.017^{*}$ \\
\hline \multirow[t]{2}{*}{ Type of pregnancy } & Singleton & 1 & & & 1 & & \\
\hline & Multiple & 6.6 & $3.7-11.7$ & $<0.001$ & 8.6 & $4 \cdot 5-16.5$ & $<0.001^{*}$ \\
\hline \multirow[t]{2}{*}{ Complication } & No & 1 & & & 1 & & \\
\hline & Yes & 3.1 & $2.1-4.7$ & $<0.001$ & 2.7 & $1.3-5 \cdot 3$ & $0.004 *$ \\
\hline \multirow{4}{*}{$\begin{array}{l}\text { Cervical } \\
\text { incompetence } \\
\text { Polyhydramnios }\end{array}$} & No & 1 & & & 1 & & \\
\hline & Yes & 17.7 & $2.3-134 \cdot 1$ & 0.005 & 11.6 & $1.1-121.5$ & $0.04 *$ \\
\hline & No & 1 & & & 1 & & \\
\hline & Yes & 14.5 & $3.4-61.2$ & $<0.001$ & 8.3 & $1.7-40.2$ & $0.008 *$ \\
\hline
\end{tabular}




\section{Discussion}

In this study, it was found out that antenatal care visit is one of most effective interventions in avoiding adverse pregnancy outcomes. When it is sought early in the pregnancy it is possible to detect reproductive health risk factors. In Tanzania, antenatal care (ANC) attendance is poor, as it is estimated that more than $90 \%$ of pregnant women attend antenatal care clinic at least once and only $62 \%$ four times or more (TDHS, 2010). In this study, it was found out that, about $3.1 \%$ of respondents didn't attend ANC at all. This increases the likelihood of pre-term birth by 5 times compared to those who attended ANC as recommended. Similar findings have been reported by other studies elsewhere (al-Eissa \& Ba'Aqeel, 1994; Nguyen et al., 2004; Heaman et al., 2005; Debiec et al., 2010). Also attendance to public prenatal care unit was found to be protective factor against pre-term birth.

In this study, untreated urinary tract infections were found to be a significant risk factor for pre-term birth. Similarly, significant association have been observed in other studies (AlDabbagh \& Al-Taee 2006; Bánhidy et al., 2007; Mazor-Dray et al., 2009; Alijahan et al., 2014). Urinary tract infections can weaken the membranes of the amniotic sac around the baby. This could lead to premature rupture of the membranes and preterm labour (Devlieger et al., 2006). However, other studies have revealed different results for an association between UTI and preterm birth (Chen et al., 2010). The result from regression analysis shows that untreated abnormal vaginal discharge during pregnancy has been associated with the increased likelihood of preterm birth. Similar results have been reported elsewhere (Breugelmans et al., 2010; Brocklehurst et al., 2013). The potential role of vaginal infection in spontaneous preterm birth has remained controversial.

Cervical incompetence was significantly associated with preterm delivery in our study. A previous study in Hungary has shown significant association between cervical incompetence and preterm births (Bánhidy et al., 2010). Cervical incompetence may cause preterm birth during the second and third trimester. In a woman with cervical incompetence, dilatation and effacement of the cervix may occur without pain or uterine contractions. The aetiologies of cervical incompetence are highly variable (Jewelewicz, 1991). Cervical incompetence occurs because of the weaknesses of the muscles of the cervix. Complications during pregnancy were also found to be significantly associated with pre-term birth. Similar results have been reported by different other studies (al-Eissa \& Ba'Aqeel, 1994; Martius et al., 1998; Grjibovski et al., 2005; Kim et al., 2005; Mann et al., 2011). Presence of polyhydramnios increases the risk of preterm delivery. Similar findings have been reported in developed countries (Many et al., 1995; Tough et al., 2003).

One of the major limitations of this study is recall bias. However, this was reduced as the factors assessed were related to pregnancy and mothers were interviewed soon after delivery.

Recognizing the high burden of preterm births in resource poor setting country like Tanzania, this study has identified several risk factors for preterm birth, and consequently. The findings of this study calls for planners to design community-based interventions to address complications from preterm birth. From a programme planning standpoint, it is important to take risk factors for preterm birth into account, since addressing women at higher risk could help reduce preterm births. Overall, given the range of unpredictability of preterm birth risks, similar studies should be conducted to generate more population-based evidence on burden and risk factors of preterm birth in developing countries.

\section{Acknowledgements}

The authors thank all the respondents who participated in this study for their enthusiasm. We are also most grateful to Neema Shirima, Mary Komba and Odillo Byabato for their remarkable assistant. This work was financially supported by Ministry of Health and Social welfare. 


\section{References}

Al-Dabbagh, S.A. \& Wafa, Y.A. (2006) Risk factors for pre-term birth in iraq: a case-control study. $B M C$ Pregnancy and Childbirth 6: 13.

al-Eissa, Y.A. \& Ba'Aqeel, H.S. (1994) Risk Factors for Spontaneous Preterm Birth in a Saudi Population. European Journal of Obstetrics, Gynecology and Reproductive Biology 57, 1924.

Alexander, Greg, R. (2007) Prematurity at birth: determinants, consequences, and geographic variation - preterm birth. In: R.E. Berhrman \& Adrienne Stith Butler: Preterm Birth: Causes, Consequences, and Prevention. National Academies Press, Washington.

Alijahan, R., Sadegh, H., Mehrdad M., Farhad, P. \& Peymaneh, A.H. (2014) Prevalence and risk factors associated with preterm birth in Ardabil, Iran. Iranian Journal of Reproductive Medicine 12, 47-56.

Bánhidy, F., Acs, N., Puhó, E.H. \& Czeizel, A.E. (2007) Pregnancy complications and birth outcomes of pregnant women with urinary tract infections and related drug treatments. Scandinavian Journal of Infectious Diseases 39, 390-397.

Bánhidy, F, Acs, N., Puhó, E.H. \& Czeizel, A.E. (2010) Association of very high Hungarian rate of preterm births with cervical incompetence in pregnant women. Central European Journal of Public Health 18, 8-15.

Beck, S., Wojdyla, D., Say, L., Betran, A.P., Merialdi, M., Requejo, J.H., Rubens, C., Menon, R. \& van Look, P.F.A. (2010) The worldwide incidence of preterm birth: a systematic review of maternal mortality and morbidity. Bulletin of the World Health Organization 88, 31-38.

Blencowe, H., Lee, A.C., Cousens, S., Bahalim, A., Narwal, R., Zhong, N., Chou, D., Say, L., Modi, N., Katz, J., Vos, T., Marlow, N. \& Lawn, J.E. (2013) Preterm birth-associated neurodevelopmental impairment estimates at regional and global levels for 2010. Pediatric Research 74 (Suppl 1), 17-34.

Breugelmans, M., Vancutsem, E., Naessens, A., Laubach, M. \& Foulon, W. (2010) Association of abnormal vaginal flora and ureaplasma species as risk factors for preterm birth: a cohort study. Acta Obstetricia et Gynecologica Scandinavica 89, 256-260.

Brocklehurst, P., Gordon, A., Heatley, E. \& Milan, S.J. (2013) Antibiotics for treating bacterial vaginosis in pregnancy. The Cochrane Database of Systematic Reviews 1: CDo00262.

Chen, Y.K., Chen, S.F., Li, H.C. \& Lin, H.C. (2010) No increased risk of adverse pregnancy outcomes in women with urinary tract infections: a nationwide population-based study. Acta Obstetricia et Gynecologica Scandinavica 89, 882-888.

Cooper, R., Atherton, K. \& Power, C (2009) Gestational age and risk factors for cardiovascular disease: evidence from the 1958 British birth cohort followed to mid-life. International Journal of Epidemiology 38, 235-244.

Debiec, K.E., Paul, K.J., Mitchell, C.M. \& Hitti, J.E. (2010) Inadequate prenatal care and risk of preterm delivery among adolescents: a retrospective study over 10 years. American Journal of Obstetrics and Gynecology 203, 122.e1-6.

Devlieger, R., Millar, L.K., Bryant-Greenwood, G., Lewi, L. \& Deprest, J.A. (2006) Fetal membrane healing after spontaneous and iatrogenic membrane rupture: a review of current evidence. American Journal of Obstetrics and Gynecology 195, 1512-1520.

Gondwe, A., Alister, C.M., Per A. \& Ulla A. (2014) Perceptions and experiences of community members on caring for preterm newborns in rural Mangochi, Malawi: a qualitative study. BMC Pregnancy and Childbirth 14 (1).

Grjibovski, A.M., Bygren, L.O., Yngve, A. \& Sjöström, M. (2005) Large social disparities in spontaneous preterm birth rates in transitional Russia. Public Health 119 (2): 77-86.

Heaman, M.I., James, F.B., Annette, L.G., Michael, E.K. \& Raymond F.C. (2005) Risk factors for spontaneous preterm birth among aboriginal and non-aboriginal women in Manitoba. Paediatric and Perinatal Epidemiology 19, 181-193. 
Jewelewicz, R. (1991) Incompetent cervix: pathogenesis, diagnosis and treatment. Seminars in Perinatology 15, 156-161.

Kim, Y.J., Lee, B.E., Park, H.S., Kang, J.G., Kim, J.O. \& Ha, E.H. (2005) Risk factors for preterm birth in Korea: a multicenter prospective study. Gynecologic and Obstetric Investigation 60, 206-212.

Lawn, J.E., Davidge, R., Paul, V.K., von Xylander, S., de Graft, J., Costello, A., Kinney, M.V., Segre, J. \& Molyneux, L. (2013) Born too soon: care for the preterm baby. Reproductive Health 10 (Suppl 1): S5.

Mann, J.R., McDermott, S., Griffith, M.I., Hardin, J. \& Gregg, A. (2011) Uncovering the complex relationship between pre-eclampsia, preterm birth and cerebral palsy. Paediatric and Perinatal Epidemiology 25, 100-110.

Many, A., Hill, L.M., Lazebnik, N. \& Martin, J. G. (1995) The association between polyhydramnios and preterm delivery. Obstetrics and Gynecology 86, 389-391.

Martius, J.A., Steck,T., Oehler, M.K. \& Wulf, K.H. (1998) Risk factors associated with preterm ( $<37+0$ weeks) and early preterm birth ( $<32+0$ weeks): univariate and multivariate analysis of 106345 singleton births from the 1994 statewide perinatal survey of Bavaria. European Journal of Obstetrics, Gynecology, and Reproductive Biology 80, 183-189.

Mazor-Dray, E., Levy, A., Schalaeffer, F. \& Sheiner, E. (2009) Maternal urinary tract infection: is it independently associated with adverse pregnancy outcome? Journal of Maternal-Fetal \& Neonatal Medicine 22, 124-128.

Mpembeni, R., Jonathan, R. \& Mughamba, J. (2015) Perinatal mortality and associated factors among deliveries in three municipal hospitals of Dar es Salaam, Tanzania. Journal of Pediatrics and Neonatal Care 1 (4):00022

Murray, C.L., Vos, T., Lozano, R., Naghavi, M., Flaxman, A.D., Michaud, C. et al. (2012) DisabilityAdjusted Life Years (DALYs) for 291 diseases and injuries in 21 regions, 1990-2010: a systematic analysis for the Global Burden of Disease Study 2010. Lancet 380, 2197-2223.

NBS (2013) 2012 Population and housing census. Population distribution by age and sex: Tanzania. National Bureau of Statistics, Dar es Salaam.

Nguyen, N., Savitz, D.A. \& Thorp, J.M. (2004) Risk factors for preterm birth in Vietnam. International Journal of Gynaecology and Obstetrics 86, 70-78.

Pike, K.C. \& Lucas, J.S. (2015) Respiratory consequences of late preterm birth. Paediatric Respiratory Reviews, December. Paediatrics Respiratory Review 16, 182-188.

TDHS (2010) Tanzania Demographic and Health Survey 2010. National Bureau of Statistics, Dar es Salaam, Tanzania, ICF Macro Calverton, Maryland, USA, Report; April 2011.

Tough, S.C., Newburn-Cook, C.V., White, D.E., Fraser-Lee, N.J., Faber, A.J., Frick, C., Svenson, L.W. \& Sauve, R. (2003) Do maternal characteristics and past pregnancy experiences predict preterm delivery among women aged 20 to 34? Journal of Obstetrics and Gynaecology Canada 25, 656-666.

WHO (2015) Preterm Birth. World Health Organization. www.who.int $\% 2$ Fmediacentre $\% 2 F f a c t s h e e t s \% 2 F f s 363 \% 2 F e n \% 2 F$. 